\title{
Up-Regulation of cyr61 in Vascular Smooth Muscle Cells of Spontaneously Hypertensive Rats
}

\author{
Hiroyuki Unoki, Kenji Furukawa, Hideto Yonekura, Yoshimichi Ueda, \\ Shogo Katsuda, Mitsuko Mori, Kan-ichi Nakagawara, Hiroshi Mabuchi, and \\ Hiroshi Yamamoto
}

\begin{abstract}
Department of Biochemistry and Molecular Vascular Biology (HU, KF, HY, HY), Second Department of Internal Medicine (KF, HM), Kanazawa University Graduate School of Medical Science, Kanazawa, Department of Pathology (HU), Institute of Basic Medical Sciences, University of Tsukuba, Tsukuba, Department of Pathology (YU, SK), Kanazawa Medical University, Uchinada, and Nihon Gene Research Laboratories, Inc. (MM, KN), Sendai, Japan
\end{abstract}

SUMMARY: In the present study, we applied a fluorescent differential display method to mRNAs from aortae of spontaneously hypertensive rats (SHRs), stroke-prone spontaneously hypertensive rats (SPSHRs), and their parental strain, Wistar Kyoto rats (WKYRs), to identify the genes involved in the development of hypertension. Through this screen we came across a gene that is consistently up-regulated in hypertensive rats. Nucleotide sequence determination of the corresponding cDNA revealed that the gene is the rat orthologue of cyr61. Northern blot analysis showed that cyr61 expression increases in SHR and SPSHR before the onset of hypertension and is sustained thereafter at higher levels than in age-matched WKYRs. In situ hybridization analysis demonstrated that cyr61 is expressed strongly in smooth muscle cells (SMCs) in media of SHR and SPSHR but not WKYR aorta. Fluorescent in situ hybridization mapped the cyr61 gene to rat chromosome 1p12-13, which is located in close proximity to a recently defined quantitative trait locus including $\mathrm{NHE3} \mathrm{Na} / \mathrm{H}^{+}$exchanger. Overexpression of the cyr61 gene in stably transfected rat SMC line A7r5 caused rather inhibitory effects on the proliferation and DNA and protein synthesis. Our results thus demonstrate for the first time that cyr61 can also act as a growth inhibitor in SMC of genetically hypertensive rats. This may reveal a new route for investigation of the pathogenesis of hypertension. (Lab Invest 2003, 83:973-982).

$E$ ssential hypertension is the most prevalent cardiovascular disorder and has been recognized as a polygenic disease that probably occurs due to complex gene-to-gene and environment-to-gene interactions and their disturbances (Hamet et al, 1998). Several causal genes have been suggested as candidates for essential hypertension. However, the relationship between these genes and systemic hypertension is not yet fully understood; association and linkage studies have not necessarily given consistent results (Brand et al, 1998; Kunz et al, 1997).

The spontaneously hypertensive rat (SHR) was established as an animal model for essential hypertension by recurrent selective breeding of Wistar rats (Okamoto and Aoki, 1963). SHR and its normotensive

DOI: 10.1097/01.LAB.0000079329.07787.7F

Received April 1, 2003.

This work was supported by the Research for the Future Program of the Japan Society for the Promotion of Science (HY, Grant 97L00805); by Grants-in-Aid for Scientific Research from the Ministry of Education, Science, Culture, and Sports, Japan (HY, Grant 10670116; HU, Grant 14770069); and by a grant from the Takeda Science Foundation, Japan (HU).

Address reprint requests to: Dr. Hiroshi Yamamoto, Department of Biochemistry and Molecular Vascular Biology, Division of Cardiovascular Medicine, Kanazawa University Graduate School of Medical Science, 13-1 Takara-machi, Kanazawa 920-8640, Japan. E-mail: yamamoto@med.kanazawa-u.ac.jp counterpart would provide an opportunity to compare gene expressions or genetic changes between normal and hypertensive states to gain insights into the pathogenesis of essential hypertension. In this study, we applied the mRNA differential display method (Ito and Sakaki, 1999) to identify genes that are differently expressed in SHR and came across the rat homolog of the cyr61 gene, whose expression was consistently increased in hypertensive rats. The cyr61 gene encodes a secreted cysteine-rich heparin-binding protein and belongs to a growing family of cysteine-rich, secreted growth regulators called Cyr61/Cef10 Nov (CCN) family (Bork, 1993) including connective tissue growth factor (CTGF) (Bradham et al, 1991), Cyr61/ Cef10 (O'Brien et al, 1990), and the Nov gene (Martinerie et al, 1996). The cyr61 gene was found to be overexpressed in smooth muscle cells (SMCs) of the hypertensive rat aortae and can also act as a growth inhibitor in SMC.

\section{Results}

\section{Fluorescent Differential Display (FDD) Screening of Genes Differentially Expressed in Hypertensive Versus Normotensive Rat Aortae}

As shown in Figure 1A, it was confirmed that as SHRs aged, systolic blood pressure increased, reaching a plateau of about $230 \mathrm{mmHg}$. Stroke-prone spontaneously hypertensive rats (SPSHRs) also exhibited in- 

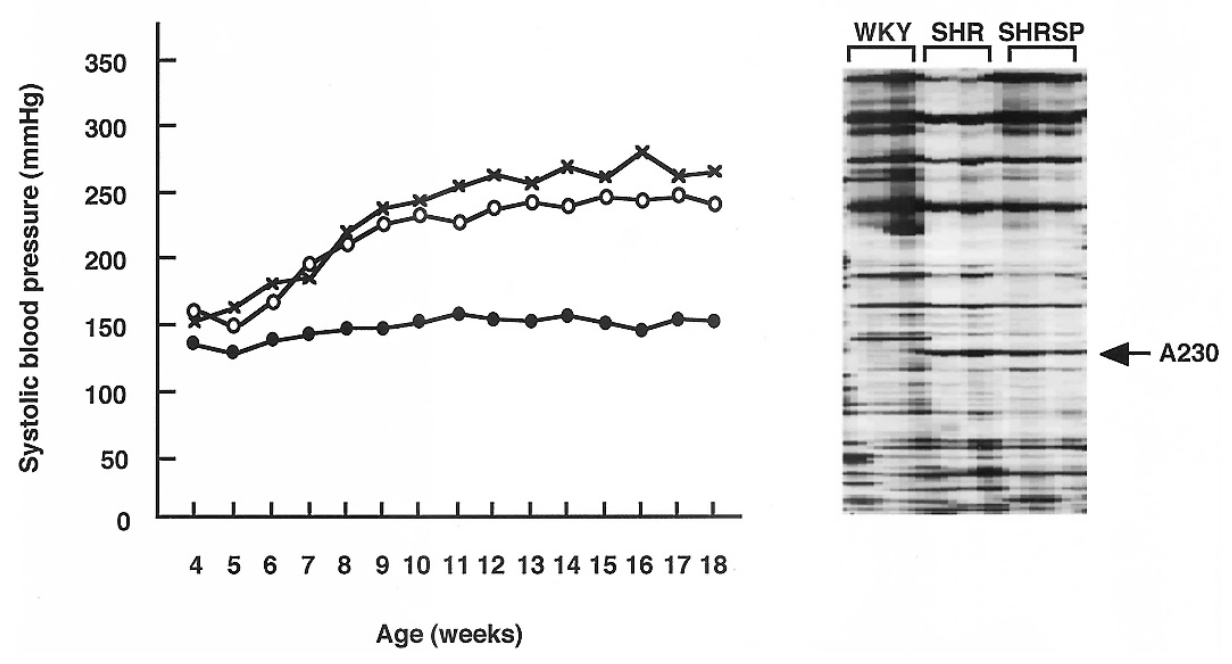

Figure 1.

Identification of mRNA activated in the aorta of hypertensive rats. (A) The development of hypertension in spontaneously hypertensive rats (SHRs) and stroke-prone spontaneously hypertensive rats (SHRSP). Line graphs show the mean values of systolic blood pressure in SHR (O), SHRSP (X) and Wistar Kyoto rat (WKYR) $(\bullet)$ $(n=20)$. (B) Differential display analysis of RNAs from aortae. 2.5- $\mu \mathrm{g}$ of total RNAs isolated from 6-week-old rats were used for the fluorescent differential display analysis. RT-PCR products were run in duplicate on adjacent lanes. Arrow indicates the product that represents the mRNA species designated A230. Essentially the same results were obtained in several experiments using different RNA samples obtained by independent isolations.

creased systolic blood pressure but from a younger age in comparison with SHR, reaching a higher level of around $250 \mathrm{mmHg}$. At 12 weeks after birth, the values recorded in SHRs and SPSHRs were 1.6- and 1.8times higher than in Wistar Kyoto rats (WKYRs), respectively. At 6 weeks, however, there were no significant differences in systolic blood pressure among the three strains (Fig. 1A). RNAs were thus isolated from aortae of 6-week-old SHRs, SPSHRs, and WKYRs and underwent FDD analysis to identify the genes that were differentially expressed in the hypertensive and normotensive rats. Fifteen candidate cDNAs were identified, and two of them had the same sequence of 296 bp in length, which was designated as A230. Figure 1B shows a typical FDD pattern, where the band corresponding to A230 was clearly marked in SHRs and SPSHRs with stronger signal intensities than in WKYR. RNA blot analysis detected a single RNA species that hybridized to the A230 FDD fragment and confirmed its elevation in SHR and SPSHR aortae (data not shown).

\section{Isolation and Sequence Determination of Full-Length A230 cDNA}

We performed 5'-rapid amplification of cDNA ends (5'-RACE) using SHR aorta-derived poly $(A)^{+}$RNA and A230-specific primers to isolate the full-length cDNA and determined the nucleotide sequence of the resultant 5'-RACE product. The cDNA was 1871-bp long and had a large open reading frame encoding a 379-amino acid protein with a 24-amino acid putative signal peptide (Fig. 2A). Searching of the DDBJ/GenBank/EMBL DNA databases revealed the highest nucleotide sequence homology $(94.6 \%)$ in the coding region between the full-length $A 230 \mathrm{cDNA}$ and mouse cyr61 cDNA (O'Brien et al, 1990). The deduced A230 protein also exhibited high homologies with mouse and human Cyr61 proteins; identity in amino acids was $93.5 \%$ and $87.9 \%$, respectively. Significant homology was also noted with the other members of the CCN family; human CTGF and NovH proteins showed $42 \%$ and $38.7 \%$ amino acid identity to the deduced A230 protein (Fig. 2A). CCN family proteins are cysteine-rich and have four conserved domains: the IGF binding protein-like domain, the von Willebrand factor type $\mathrm{C}$ repeat domain, the thrombospondin type 1 repeat domain, and the $\mathrm{COOH}$-terminal domain (Fig. 2B) (Bork, 1993). The rat A230 protein contained 38 cysteine residues, all of which were completely conserved among these family members and had $40 \%$ to $70 \%$ sequence identity with human CTGF and $\mathrm{NovH}$ in each of the four domains (Fig. 2B). From these results, we concluded that the A230 cDNA is the rat orthologue of cyr61, belonging to the $C C N$ gene family.

\section{Time Course of cyr61 mRNA Expression}

The time course of cyr61 expression in the hypertensive rat was examined. Total RNAs were isolated from the aortae of 4-, 6-, and 12-week-old hypertensive rats and age-matched WKYRs, and analyzed by Northern blotting using a 1633-bp fragment of cyr61 cDNA (nucleotides 1-1633) as a probe. As shown in Figure 3, a hybridizing band was marked at $2.6 \mathrm{~kb}$, and the mRNA level increased in SHR and SPSHR compared with that in WKYR. The levels of cyr61 mRNA were 3.6- (4-week-old SHR) and 4.7- (4-week-old SPSHR), 2.0- (6-week-old SHR) and 1.8- (6-week-old SPSHR), and 1.4- (12-week-old SHR) and 1.9- (12-week-old 


\begin{tabular}{|c|c|}
\hline $\begin{array}{l}\text { Rat } \\
\text { Mouse } \\
\text { Human } \\
\text { Human } \\
\text { NovH }\end{array}$ & $\begin{array}{l}\text { Cyr61 } \\
\text { Cyr61 } \\
\text { Cyr61 } \\
\text { CTGF }\end{array}$ \\
\hline $\begin{array}{l}\text { Rat } \\
\text { Mouse } \\
\text { Human } \\
\text { Human } \\
\text { NovH }\end{array}$ & $\begin{array}{l}\text { Cyr61 } \\
\text { Cyr61 } \\
\text { Cyr61 } \\
\text { CTGF }\end{array}$ \\
\hline $\begin{array}{l}\text { Rat } \\
\text { Mouse } \\
\text { Human } \\
\text { Human } \\
\text { NovH }\end{array}$ & $\begin{array}{l}\text { Cyr61 } \\
\text { Cyr61 } \\
\text { Cyr61 } \\
\text { CTGF }\end{array}$ \\
\hline $\begin{array}{l}\text { Rat } \\
\text { Mouse } \\
\text { Human } \\
\text { Human } \\
\text { NovH }\end{array}$ & $\begin{array}{l}\text { Cyr61 } \\
\text { Cyr61 } \\
\text { Cyr61 } \\
\text { CTGF }\end{array}$ \\
\hline $\begin{array}{l}\text { Rat } \\
\text { Mouse } \\
\text { Human } \\
\text { Human } \\
\text { NovH }\end{array}$ & $\begin{array}{l}\text { Cyr61 } \\
\text { Cyr61 } \\
\text { Cyr61 } \\
\text { CTGF }\end{array}$ \\
\hline $\begin{array}{l}\text { Rat } \\
\text { Mouse } \\
\text { Human } \\
\text { Human } \\
\text { NovH }\end{array}$ & $\begin{array}{l}\text { Cyr61 } \\
\text { Cyr61 } \\
\text { Cyr61 } \\
\text { CTGF }\end{array}$ \\
\hline $\begin{array}{l}\text { Rat } \\
\text { Mouse } \\
\text { Human } \\
\text { Human } \\
\text { NovH }\end{array}$ & $\begin{array}{l}\text { Cyr61 } \\
\text { Cyr61 } \\
\text { Cyr61 } \\
\text { CTGF }\end{array}$ \\
\hline $\begin{array}{l}\text { Rat } \\
\text { Mouse } \\
\text { Human } \\
\text { Human } \\
\text { NovH }\end{array}$ & $\begin{array}{l}\text { Cyr61 } \\
\text { Cyr61 } \\
\text { Cyr61 } \\
\text { CTGF }\end{array}$ \\
\hline
\end{tabular}

MSSSTIKT- - MSSSTFRT-- - ----LAVA -VTLLHL-TR TLALS-TCPAA C--HCPLE-A MSS-RIARA- ----LALV -VTLLHL-TR LALS-TCPAA C--HCPLE-A

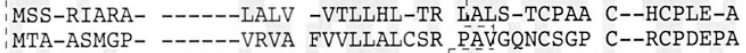
MQS-VQSTSE _CLRKQCLCLT EL-LLHLLGQ VAATQRCPPQ CPGRCPATP-

$$
* * *
$$

PKCAPGVGLV RDGCGCCKVC AKOLNEDCSK TQPCDHTKGL ECNFGANSTA PKCAPGVGLV RDGCGCCKVC AKQLNEDCSK TQPCDHTKGL ECNFGASSTA PKCAPGVGLV RDGCGCCKVC AKOLNEDCSK TOPCDHTKGL ECNFGASSTA PRCPAGVSLV LDGCGCCRVC AKOLGELCTE RDPCDPHKGL FCDFGSPANR PTCAPGVRAV LDGCSCCLVC ARQRGESCSD LEPCDESSGL YCDRSADPSN

LKGICRAOSE GRPCEYNSRI YONGESFOPN CKHOCTCIDG AVGCIPLCPO LKGICRAQSE GRPCEYNSRI YQNGESFQPN CKHQCTCIDG AVGCIPLCPQ LKGICRAQSE GRPCEYNSRI YQNGESFQPN CKHQCTCIDG AVGCIPLCPQ KIGVCTAKD- GAPCIFGGTV YRSGESFQSS CKYQCTCLDG AVGCMPLCSM QTGICTAVE- GDNCVFDGVI YRSGEKFQPS CKFQCTCRDG QIGCVPRCQI$$
*
$$$$
*
$$$$
* \quad * *
$$

ELSLPNLGCP NPRLVKVSGQ CCEEWVCDED SIKDSLDDQD DLLG----FD ELSLPNLGCP NPRLVKVSGO CCEEWVCDED SIKDSLDDOD DLLG----LD ELSLPNLGCP NPRLVKVTGO CCEEWVCDED SIKDPMEDOD GLLGKELGFD DVRLPSPDCP FPRRVKLPGK CCEEWVCDEP DVLLPEPNCP APRKVEVPGE CCEKWICGPD

$$
* * \quad *
$$

ASEVELTRNN ELIATGKGSS LKRLPVFGTE PRVLYNPLHA HGQKCIVQTT ASEVELTRNN ELIAIGKGSS LKRLPVFGTE PRVLFNPLHA HGQKCIVQTT ASEVELTRNN ELIAVGKGSS LKRLPVFGME PRILYNPLQ- -GQKCIVQTT --------- --EEDSLGG LTLAAYRPEA TLGVEVSDS- -SVNCIEQTT

SWSQCSKSCG TGISTRVTND NPECRLVKET RICEVRPCGQ PVY-SSLKKG SWSOCSKSCG TGISTRVTND NPECRLVKET RICEVRPCGO PVY-SSLKKG SWSOCSKTCG TGISTRVTND NPECRLVKET RICEVRPCGO PVY-SSLKKG EWSACSKTCG MGISTRVTND NASCRLEKQS RLCMVRPCEA DLE-ENIKKG EWTACSKSCG MGFSTRVTNR NRQCEMLKQT RLCMVRPCEQ EPEQPTDKKG

$$
\text { ** }
$$

KKCSKTKKSP EPVRFTYAGC SSVKKYRPKY CGSCVDGRCC TPLQTRTVKM KKCSKTKKSP EPVRFTYAGC SSVKKYRPKY CGSCVDGRCC TPLQTRTVKM KKCSKTKKSP EPVRFTYAGC LSVKKYRPKY CGSCVDGRCC TPOLTRTVKM KKCIRTPKIS KPIKFELSGC TSMKTYRAKF CGVCTDGRCC TPHRTTTLPV KKCLRTKKSL KAIHLOFKNC TSLHTYKPRF CGVCSDGRCC TPHNTKTIQA

$$
* \quad * \quad * * * * *
$$

$\begin{array}{ll}\text { RFRCEDGEMF SKNVMMIOSC KCNYNCPHPN EASFRLYSLF NDIHKFRD.. } & 379\end{array}$ RFRCEDGEMF SKNVMMIOSC KCNYNCPHPN EASFRLYSLF NDIHKFRD.. 379 RFRCEDGETF SKNVMMIOSC KCNYNCPHAN EAAFPFYRLF NDIHKFRD.. 381 EFKCPDGEVM KKNMMFIKTC ACHYNCPGDN -DIFESLYYR KMYGDM-A.. 349 EFQCSPGQIV KKPVMVIGTC TCHTNCPKNN EAFLQELELK TTRGKM.... 357
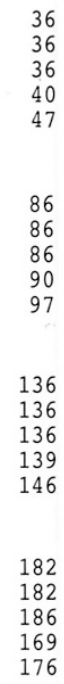

232 232

204

211

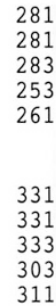

331

311

B

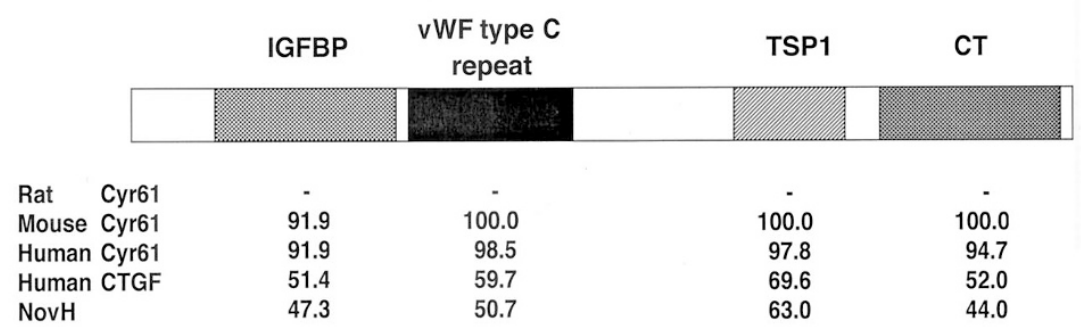

Figure 2.

Alignment of the deduced amino acid sequences of rat Cyr61, mouse Cyr61, human Cyr61, human connective tissue growth factor, and NovH proteins (A) and a schematic representation of the domain structure of rat Cyr61 protein (B). (A) Positions of the identical amino acids are shaded. Putative signal sequences are boxed by a broken line. The 38 conserved cysteine residues are shown by asterisks. (B) Numbers indicate the amino acid identity in percentage between the corresponding domains of rat Cyr61 and the other CCN family members. IGFBP = IGF binding protein-like domain; vWF = von Willebrand factor; TSP1 = thrombospondin type 1 repeat domain; $C T=\mathrm{COOH}$-terminal domain. The nucleotide sequence data reported in this paper have been deposited in the DDBJ/EMBL/GenBank nucleotide sequence databases with the accession number AB015877.

SPSHR) fold higher than those in the age-matched WKYR, respectively (Fig. 3). No statistically significant difference was observed in the cyr61 mRNA level between SHR and SPSHR.

\section{Tissue Distribution of cyr61 mRNA}

The tissue distribution of cyr61 gene expression was then examined by Northern blotting in 6-week-old 

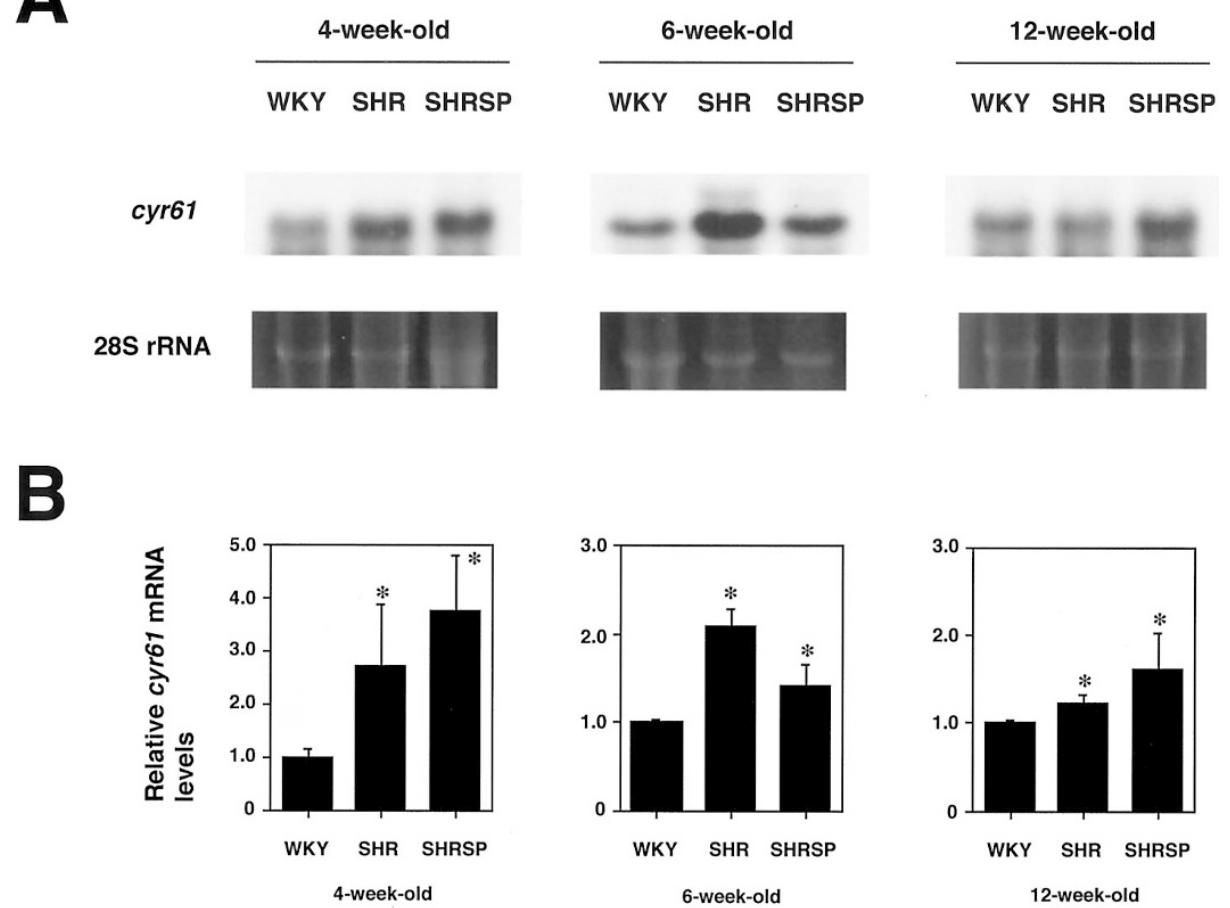

Figure 3.

Time course changes of cyr61 expression in the aorta. (A) Northern blot analysis of total RNAs derived from the aorta of 4-, 6-, and 12-week-old rats. Acrydine orange stain of 28S rRNA is shown in the lower panel. (B) Quantification of the cyr61 mRNA levels. Intensities of the cyr61 signals were normalized with those of $28 \mathrm{~S}$ rRNA and are related to the values of Wistar Kyoto rat. Values are expressed as the mean $\pm \mathrm{SD}(n=5) .{ }^{*} p<0.05$.

WKYRs. It revealed a relatively wide distribution of cyr61 expression, but the highest expression was noted in the aorta (Fig. 4). The mRNA of cyr61 was present at moderate levels in the heart, skeletal muscle, kidney and lung, and at lower levels in the small intestine, adrenal grand, brain, and liver (Fig. 4). This pattern of cyr61 expression was consistent with the previous reports on mouse and human cyr61 expressions (Jay et al, 1997; O'Brien et al, 1990; Perbal et al, 1999).

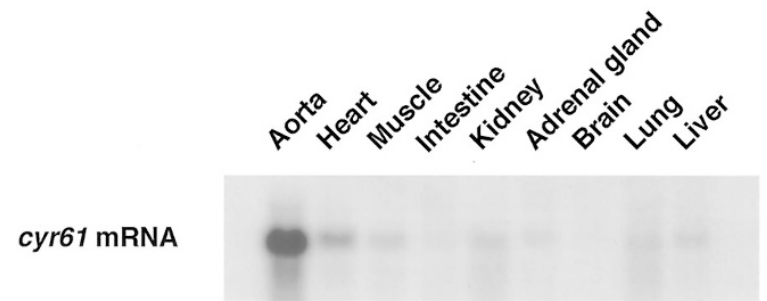

$28 \mathrm{~S}$ rRNA

Figure 4.

Tissue distribution of cyr61 mRNA. Twenty-five $\mu \mathrm{g}$ of total RNAs from the indicated Wistar Kyoto rat tissues were subjected to electrophoresis on a 1.5\% agarose gel containing $1.1 \mathrm{M}$ formaldehyde and hybridized with ${ }^{32} \mathrm{P}$-labeled rat cyr61 CDNA probe. 28S rRNA was used as the reference standard.

\section{In Situ Detection and Localization of cyr61 mRNA in Rat Aortae}

To identify the cell types that express the cyr61 gene, we performed an in situ hybridization analysis of the aortae from 6-week-old SHRs, SPSHRs, and WKYRs. In WKYR blood vessels, only weak signals were detected in fibroblasts in the adventitia (Fig. 5A). In contrast, strong cyr61 mRNA-derived signals were marked in SMC in the medial layer of SHR and SPSHR blood vessels (Fig. 5, C to E). Fibroblasts in SHR and SPSHR aortae showed a moderate expression of cyr61 mRNA as in the WKYR blood vessels. Microscopic observation disclosed no hyperplasia of SMC in hypertensive rat arteries at this stage (Fig. 5F).

\section{Chromosomal Mapping of Rat cyr61 Locus}

Congenic approaches have delimited candidate loci for hypertensive traits in SHR (Hamet et al, 1998; Wakeland et al, 1997). Accordingly, to determine whether the cyr61 gene resides within these loci, we then mapped the chromosomal localization of rat cyr61 gene by fluorescent in situ hybridization (FISH) using the cyr61 genomic fragment as a probe (Fig. 6). Of a total of 100 hybridizing signals observed, 90 $(90 \%, p<0.01)$ were localized over 1p12-13 (Fig. 6A). Of the 90 chromosome 1 analyzed, 80 had labeling on both chromatids, and 10 were labeled on a single chromatid (Fig. 6B). 

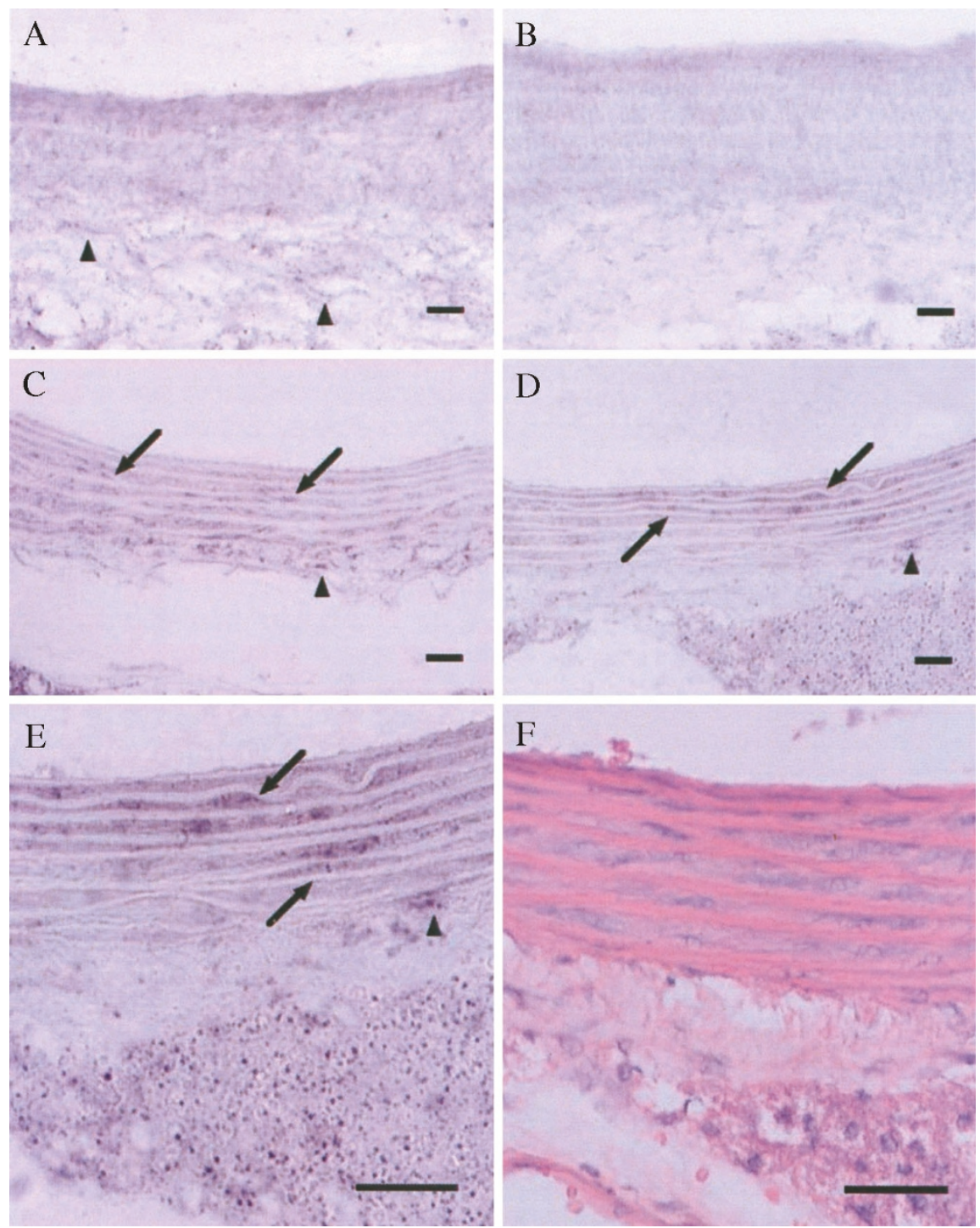

Figure 5.

Localization of cyr61 mRNA in rat blood vessels. In situ hybridization analysis of the arteries of 6-week-old Wistar Kyoto rats (A), spontaneously hypertensive rats (C), and stroke-prone spontaneously hypertensive rats (D) using digoxigenin (DIG)-labeled cyr61 antisense riboprobe. (F) Hematoxylin-eosin staining of the SPSHR artery, showing the absence of hyperplasia of smooth muscle cell (SMC). (E) Higher magnification of D. (B) Control experiment with DIG-labeled cyr61 sense probe; the section was from 6-week-old SPSHR as were D and E. Arrowheads indicate cyr61 mRNA-derived signals in fibroblasts. Arrows indicate cyr61 mRNA-derived signals in SMC. Scale bar indicates $100 \mu \mathrm{m}$.

\section{Cyr61 Transfection into SMC}

To examine the roles of cyr61 in the hypertensive process, we established rat SMC line A7r5, which overexpresses Cyr61 proteins. The proteins were recovered in conditioned media of Cyr61-A7r5 cells (see "Materials and Methods" section), and quantitatively bound to and salt-eluted from heparin-Sepharose column (data not shown), being consistent with the previous report (Kireeva et al, 1996). The recombinant Cyr61 was confirmed by Western blot analysis to contain histidine tag at its $\mathrm{C}$-terminal and to migrate to the position of about $36 \mathrm{kd}$ as expected (Fig. 7A). The recombinant Cyr61 proteins were not detected in media from A7r5 cells transfected with the pcDNA3 vector alone.

\section{Effects of Cyr61 Overexpression on A7r5 Cell Proliferation}

Cyr61 overexpression showed rather inhibitory effects on cell proliferation and macromolecular synthesis. The growth curve shifted downward in Cyr61-A7r5 cells compared with the A7r5 parental line (Fig. 7B). Thymidine and leucine incorporation was also significantly reduced by Cyr61 overexpression (Fig. 7C). A series of experiments with another cyr61 overexpressor clone revealed a similar tendency (data not shown).

\section{Discussion}

In the present study, an FDD screen led to the isolation of a new rat gene that was differently expressed in the 


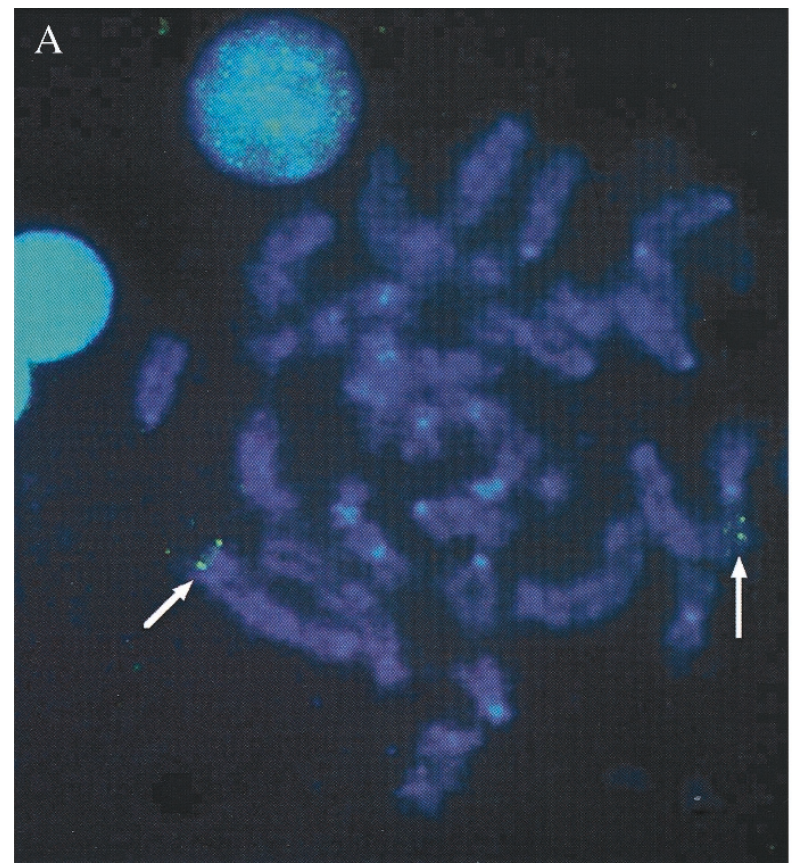

Single signal 0000000000
Twin signals

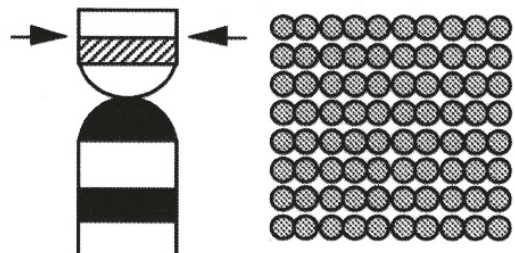

Figure 6.

Chromosomal localization of rat cyr61 by fluorescence in situ hybridization. (A) R-banded metaphase chromosomes showing the localization of spots on both chromatids of chromosome 1. Metaphase chromosomes were spread from rat bone marrow cells and hybridized to the biotin-labeled cyr61-genomic fragment (4.8 $\mathrm{kbp}$ ), which was then visualized with fluorescein isothiocyanate-conjugated streptavidin. Arrows indicate fluorescent signals on 1p12-13. Q-band-like image of the same metaphase is overlapped. (B) Ideogram depicting the distribution of fluorescent spots over chromosome 1. Dotted circle indicates 1 chromosome with twin signals; open circle indicates 1 chromosome with a single signal.

A

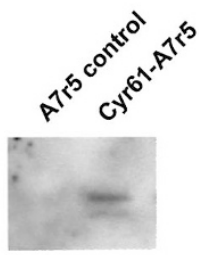

B

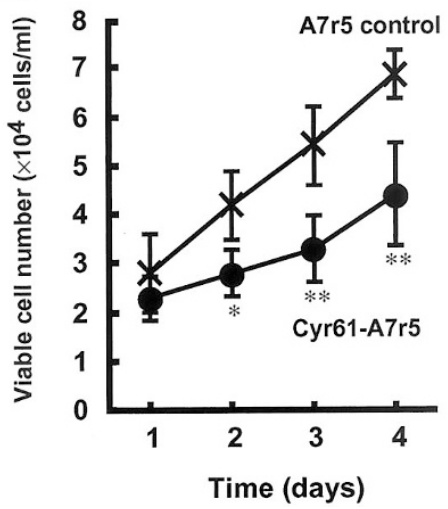

C

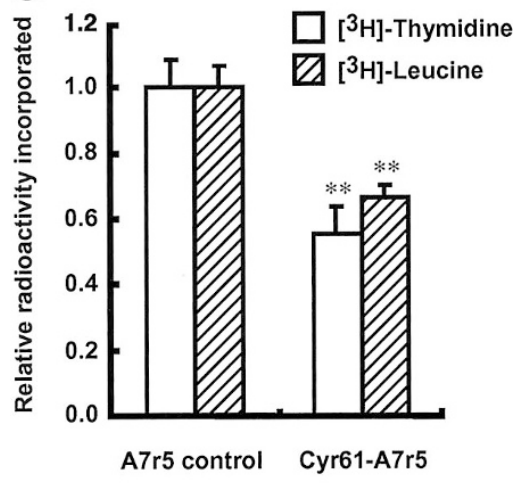

Figure 7.

Overexpression of Cyr61 protein in A7r5 cells. (A) Representative Western blot of Cyr61 protein in A7r5 cells. Conditioned media of A7r5 control cells (Lane 1) or Cyr61-A7r5 cells (Lane 2) were loaded onto a HiTrap Heparin column. Proteins were eluted from the column with 0.4 to $0.6 \mathrm{M} \mathrm{NaCl}$ and were analyzed by $10 \%$ SDS-PAGE followed by Western blotting with antipenta His antibodies as probe. (B) Effects of Cyr61 overexpression on viable cell number. Results are given as the growth of Cyr61-A7r5 cells $(\bullet)$ and A7r5 control cells $(\times)$. Values are expressed as the mean \pm SD $(n=4)$. (C) Effects of Cyr61 overexpression on DNA and protein syntheses. Values are expressed as the mean $\pm \mathrm{SD}(n=3)$. Experimental conditions are described in "Materials and Methods" section. ${ }^{*} p<0.05 ;{ }^{\star *} p<0.01$.

aortae of SHRs and SPSHRs. The isolation and sequence determination of the near full-length cDNA revealed that it was the rat orthologue of cyr61. The cyr61 gene was first identified as a growth factorinducible immediate early gene in mouse fibroblasts, and so designated because it encodes a secreted cysteine-rich heparin-binding protein (O'Brien et al, 1990). We examined the expression of the cyr61 gene in the aorta during the course of the development of hypertension. Even before the onset of hypertension, cyr61 mRNA levels were consistently higher in SHR and SPSHR aortae than in age-matched WKYR aortae (Fig. 3). The blood vessel was found to express cyr61 at the highest level among the tissues examined (Fig. 4). In situ hybridization study revealed that the cyr61 mRNA was strongly expressed in SMC at the medial layer of the aorta in SHRs and SPSHRs (Fig. 5). FISH analysis defined the cyr61 gene locus at rat chromosome 1p12-13, which resides adjacent to a recently defined blood pressure quantitative trait locus having 
the candidate gene S/c9a3 for sodium-hydrogen exchange (Fig. 6) (Saad et al, 2001). Slc9a3 encodes $\mathrm{Na}^{+} / \mathrm{H}^{+}$exchanger 3 (NHE3), which is one of five plasma membrane $\mathrm{Na}^{+} / \mathrm{H}^{+}$exchangers and is expressed in the kidney (Tse et al, 1992). In S/c9a3 ${ }^{-/-}$ mice, there is a severe absorptive defect in the kidney and intestine, which causes reduced blood pressure (Schultheis et al, 1998). In the present study, we established rat vascular SMC lines that overexpress Cyr61 proteins and showed that Cyr61 rather inhibited SMC proliferation and DNA and protein syntheses (Fig. 7). In contrast to our results, previous studies reported growth factor-induced mitogenic effects of Cyr61 in fibroblasts (Kireeva et al, 1996) and endothelial cells (Kolesnikova and Lau, 1998). Recent studies have shown that cyr61 expression is induced in arterial SMC following balloon angioplasty (Grzeszkiewicz et al, 2002) and that cyr61 may regulate the process of wound repair, including angiogenesis, inflammation, extracellular matrix remodeling, and cell-matrix interactions (Chen et al, 2001). Because the expression of cyr61 has been reported to be under the control of growth factors, among which basic fibroblast growth factor (bFGF) is known as the principal inducer (Lau and Lam, 1999), the possibility that inducible expression of cyr61 is regulated by growth factors such as bFGF cannot be ruled out. We assayed the bFGF contents in SHR, SPSHR, and WKYR blood vessels and observed no significant change in bFGF levels among them, suggesting that the induction of cyr61 expression in SMC cannot be primarily ascribed to bFGF. Others also demonstrated that cyr61 expression in SMC is influenced by blood pressure in vitro (Tamura et al, 2001).

Angiotensin II acts as an important mediator in cardiovascular diseases such as hypertension, congestive heart failure, and renal failure. Recent studies have shown that angiotensin II stimulated cyr61 expression in SMC via $\mathrm{AT}_{1}$ receptor signaling (Hilfiker et al, 2002). The fact that in human atherosclerotic lesions Cyr61 expression is colocalized with angiotensin II suggests a new role of cyr61 in atherosclerosis (Hilfiker et al, 2002). CTGF, another member of the CCN family, has been shown to be overexpressed in vascular SMC and in luminal and vasa vasorum endothelial cells of advanced atherosclerotic lesions (Oemar et al, 1997). CTGF promotes the growth of fibroblasts (Frazier et al, 1996) and endothelial cells (Shimo et al, 1998) but inhibits the proliferation of SMC (Hishikawa et al, 1999, 2000). The precise mechanism of action of the CCN family members remains to be determined. Further studies on the biological function of $\mathrm{CCN}$ family members should provide a new clue for understanding the pathogenesis of blood pressure elevation and vascular derangement in hypertension.

In conclusion, the present study has demonstrated for the first time that cyr61 is overexpressed in hypertensive rat aortae and inhibits cell proliferation and growth of SMC. Despite recent therapeutic advances, essential hypertension continues to be the major problem affecting the progression of atherosclerosis and diabetic angiopathy. The overexpression of cyr61 may exert an important role in artery remodeling during the development and establishment of hypertension and thus present a potential target of therapeutic intervention that warrants further investigation.

\section{Materials and Methods}

\section{Animals}

Male SHRs (SHR/lzm), SPSHRs (SPSHR/Izm), and WKYRs (WKYR/Izm) were obtained from the Disease Model Company-Operative Research Association (Kyoto, Japan). Rats were housed two per container and fed standard rat chow and water. All experiments were conducted in accordance with the institutional guidelines of the Takara-machi campus of Kanazawa University.

\section{Measurements of Blood Pressure}

Twenty male rats were used for indirect blood pressure measurements with a UR-5000 instrument (Elquest Corporation, Tokyo, Japan). The tail cuff method was carried out as previously reported (Ikeda et al, 1991). Three consecutive consistent readings were taken in each individual, and the values were averaged.

\section{Isolation of Aortae}

Aortae encompassing the beginning of the thoracic segment to the aortic bifurcation were extirpated under anesthesia from 4-, 6-, or 12-week-old SHRs, SPSHRs, and WKYRs and washed with Hank's balanced salt solution. After dissecting off loose periadventitial connective tissues, the aortae were frozen in liquid nitrogen and stored at $-80^{\circ} \mathrm{C}$ until RNA isolation.

\section{Isolation of RNAs}

The frozen aortae were disrupted in TRIZOL Reagent (Invitrogen Corporation, Carlsbad, California) using a Polytron homogenizer (KINEMATICA AG, Littau/Luzern, Switzerland) at the maximum speed for $30 \mathrm{sec}-$ onds, and total RNAs were isolated according to the manufacturer's instructions. For 5'-RACE, poly $(A)^{+}$ RNAs were isolated from the total RNAs using QuickPrep mRNA Purification Kit (Amersham Biosciences Corporation, Piscataway, New Jersey). The RNA concentration was determined by measuring absorbance at $260 \mathrm{~nm}$.

\section{FDD Analysis}

FDD analysis was performed according to the method developed by others (Ito and Sakaki, 1999). Total RNAs $(2.5 \mu \mathrm{g})$ from aortae of 6-week-old SHRs, SPSHRs, and WKYRs were reverse-transcribed with Texas red-labeled 3'-anchored oligo-dT primer (Texas red- $\mathrm{T}_{15} \mathrm{~N}$; $\mathrm{N}$ is either $\mathrm{A}, \mathrm{C}$, or $\mathrm{G}$ ) and SuperScript II RNase $\mathrm{H}^{-}$Reverse Transcriptase (Invitrogen Corporation), and the resultant reverse-transcribed products were used as templates for PCR. PCR was performed 
with an arbitrary primer (GenHunter Corporation, Nashville, Tennessee), the same 3'-anchor primer and GeneTaq Polymerase (Nippon Gene, Toyama, Japan). The amplification products were separated by denaturing $6 \%$ polyacrylamide gel electrophoresis, and the patterns of DNA fragments were analyzed with a Hitachi SQ-5500 sequencer (Hitachi Inc., Tokyo, Japan). The reproducibility of the experiment was confirmed in several independent experiments.

\section{Cloning and Sequencing of cDNA Fragments of Interest}

cDNAs that gave different signal intensities on FDD were recovered from the gel by excision and extraction with hot water. The recovered DNA was then re-amplified using the same set of primers and ligated to a pCR2.1 vector (Invitrogen Corporation) to transform Escherichia coli XL1-blue cells (Stratagene, La Jolla, California). Recombinant plasmid DNA was purified from the bacterial culture using Flexiprep Kit (Amersham Biosciences Corporation). Nucleotide sequences of cloned cDNA fragments were determined with the Hitachi SQ-5500 sequencer or with an Applied Biosystems 377 DNA sequencer (The PerkinElmer Corporation, Foster City, California) by the dideoxy chain termination method (Sanger et al, 1977).

\section{Northern Blot Analysis}

Twenty-five $\mu \mathrm{g}$ of total RNAs from aortae of 4-, 6-, and 12-week-old WKYRs, SHRs, and SPSHRs underwent agarose gel electrophoresis and filter blot hybridization as described previously (Yonekura et al, 1999). The cDNA fragments were labeled by the random priming method using $\left[\alpha{ }^{-32}\right.$ P]dCTP (NEN Life Science Products, Inc., Boston, Massachusetts). The radioactivities of the hybridized bands were measured with a Fujix BAS 1000 Biolmage analyzer (Fuji PhotoFilm Company Ltd., Hamamatsu, Japan). The equivalency and intactness of the loaded RNA were assessed by acrydine orange staining of $28 \mathrm{~S}$ and $18 \mathrm{~S}$ ribosomal RNAs.

\section{Isolation of Full-Length cDNA}

To obtain the full-length cDNA, the 5'-RACE was carried out using Marathon cDNA Amplification Kit (BD Biosciences Clontech, Palo Alto, California) and Klentaq polymerase mix (BD Biosciences Clontech) with a primer 5'-TCC ACT GGG GAA GGC AGG AGA G-3', the complement of the $5^{\prime}$-terminal region of the FDD-selected cDNA fragment. The amplified DNA fragments were cloned into the plasmid vector pCR2.1 and purified for sequence analysis. Both strands of the cDNA were sequenced. The cDNA sequence was analyzed for similarity with nucleotide sequences deposited in DDBJ/EMBL/GenBank databases by the BLAST algorithm.

\section{mRNA Localization by In Situ Hybridization}

Aortae from 6-week-old SHRs, SPSHRs, and WKYRs were analyzed by an in situ hybridization technique using digoxigenin (DIG)-labeled RNA probes with slight modification (Oemar et al, 1997). In brief, tissues were frozen in liquid nitrogen, and serial $10-\mu \mathrm{m}$ cryosections of thoracic arteries were mounted on silanecoated slides and fixed in $4 \%$ buffered paraformaldehyde for 10 minutes. The sections were carbethoxylated with $0.1 \%$ diethylpyrocarbonate in PBS twice for 15 minutes and subjected to hybridization. Riboprobes were prepared from a plasmid pBS (Stratagene) carrying a 586-bp EcoRl/Pstl fragment of the cloned rat cyr61 cDNA (439-1024 nucleotide). The plasmid was linearized by digestion with EcoRI (to prepare the antisense riboprobe) or Hindlll (to prepare the control sense probe). The probes were labeled with DIG-11-UTP using a DIG RNA-labeling kit (F. Hoffmann-La Roche Ltd., Basel, Switzerland). Sections were hybridized with DIG-RNA probes, and the presence of riboprobe-mRNA duplex was visualized with NBT/BCIP. The sections were mounted with Crystal/Mount (Biomeda Corporation, Foster City, California) and observed under a light microscope.

\section{FISH Analysis of Rat Chromosomes}

The FISH procedure was carried out essentially as described previously (Nakagawara et al, 1995). The DNA probe used for FISH was prepared as follows. Because the nucleotide sequence of the rat cyr61 gene was not known and because rat and mouse genes generally show strong structural conservation, we designed several sets of PCR primers based on the mouse cyr61 genomic sequence (Latinkic et al, 1991) and used them to amplify the rat equivalent with high molecular weight DNA from the liver of WKYR as a template. A set of primers, 5'- GTT ACG TCT GGT GTC TGA TTC ACC ATC TGG -3' and 5'- ATT CCA GTA TTA CAT TTC CCC TCC CTC CCC -3', and rTth DNA Polymerase XL (The Perkin-Elmer Corporation) yielded a single amplified product of the expected size (4.8 kbp). The amplified DNA was cloned into pCRIITOPO (Invitrogen Corporation) and sequence-verified. Metaphase chromosomes prepared from rat bone marrow cells were hybridized with the biotin-labeled DNA probes, and hybridized loci were visualized with fluorescein isothiocyanate-conjugated streptavidin. The chromosomes were counter-stained with 4',6diamidino-2-phenylindole, and observed under a fluorescence microscope (Olympus Corporation, Tokyo, Japan).

\section{DNA Transfection}

A 1230-bp fragment carrying the entire coding region of cyr61 cDNA and C-terminal six-times repeated histidine sequence was amplified by RT-PCR using rat aorta poly $(A)^{+}$RNA as a template and a set of primers, 5'-AGG GAT CCG GCT TIT GTT GGT TCT GTG TCG C-3' and 5'-TCA GAT CTT TAT TAG TGA TGG TGA TGA TGA TGG TCC CTG AAC TTG TGG ATA TCG-3', corresponding to nucleotides 1 to 18 and 1166 to 1187 of the rat cyr61 cDNA. The amplified DNA was inserted into the BamHI/EcoRI cloning site of the 
cytomegalovirus controlled mammalian expression vector pcDNA3 (Invitrogen Corporation) containing Neomycin resistance gene as a selection marker, and sequence-verified. The resultant plasmid was transfected into rat aortic cell line A7r5 (ATCC: CRL 1444) with Lipofectin (Invitrogen Corporation) according to the manufacturer's protocol. Stable transformants were selected in media containing G418 (Invitrogen Corporation), and designated as Cyr61-A7r5. pcDNA3 vector alone was used as control.

\section{Western Blot Analysis}

Conditioned media of Cyr61-A7r5 cells were applied to HiTrap Heparin (Amersham Biosciences Corporation) column at $4^{\circ} \mathrm{C}(1 \mathrm{ml}$ column for $10 \mathrm{ml}$ media). The column was washed with $10 \mathrm{~mm}$ sodium phosphate ( $\mathrm{pH}$ 7.0), and bound proteins were subsequently eluted with increasing concentrations of $\mathrm{NaCl}(0.2$ to $2.0 \mathrm{M}$ ) in the same buffer. The column fractions were analyzed by $10 \%$ sodium dodecyl sulfatepolyacrylamide gel electrophoresis followed by Western blotting. Western blots were probed with antipenta His antibodies (Qiagen $\mathrm{GmbH}$, Hilden, Germany) and stained with enhanced chemiluminescence detection reagents (Amersham Biosciences Corporation). Conditioned media of pcDNA3transfected A7r5 cells were used as a control.

\section{Assays for Cell Proliferation and DNA and Protein Syntheses}

Cyr61-A7r5 and A7r5 control cells were cultured for various time periods, and the number of viable cells were counted using CellTiter-Glo Luminescent Assay System (Promega Corporation, Madison, Wisconsin) according to the manufacturer's protocol with a luminometer (MTP-700CL, Corona Electronic Company, Ibaraki, Japan). We confirmed that a serum-stimulated increase in cell number is associated with increased luminescence. DNA and protein syntheses were evaluated by the incorporation of $\left[{ }^{3} \mathrm{H}\right]$ thymidine and $\left[{ }^{3} \mathrm{H}\right]$ leucine (NEN Life Science Products, Inc.), respectively, into acid-insoluble materials essentially according to the previous description (Hatakeyama et al, 1994). Briefly, Cyr61-A7r5 cells were seeded in six well plates at a density of $1 \times 10^{5}$ cells/well, and grown for 2 days in Dulbecco's modified Eagle medium (Life Technologies, Inc.) supplemented with 10\% FBS. Then the cells were pulsed either with $\left[{ }^{3} \mathrm{H}\right]$ thymidine or $\left[{ }^{3} \mathrm{H}\right]$ leucine for 12 hours at a final activity of $1 \mu \mathrm{Ci} / \mathrm{ml}$. After incubation, cells were fixed with ice-cold 10\% (w/v) trichloroacetic acid, and the resultant acidinsoluble materials were processed for liquid scintillation counting.

\section{Statistical Analysis}

All experiments were performed at least three times. Data were combined and expressed as the mean \pm SD. Statistical significance was determined using oneway ANOVA. A value of $p<0.05$ was considered significant.

\section{Acknowledgements}

We thank Drs. Masayuki Yamamoto and Ken Itoh (Department of Molecular and Developmental Biology, Institute of Basic Medical Sciences, University of Tsukuba, Japan) for protein purification; Shin-ichi Matsudaira, Reiko Kitamura, and Tomoko Yachi for technical assistance; and Brent Bell for reading the manuscript.

\section{References}

Bork P (1993). The modular architecture of a new family of growth regulators related to connective tissue growth factor. FEBS Lett 327:125-130.

Bradham DM, Igarashi A, Potter RL, and Grotendorst GR (1991). Connective tissue growth factor: A cysteine-rich mitogen secreted by human vascular endothelial cells is related to the SRC-induced immediate early gene product CEF-10. J Cell Biol 114:1285-1294.

Brand E, Chatelain N, Keavney B, Caulfield M, Citterio L, Connell J, Grobbee D, Schmidt S, Schunkert H, Schuster H, Sharma AM, and Soubrier F (1998). Evaluation of the angiotensinogen locus in human essential hypertension: A European study. Hypertension 31:725-729.

Chen CC, Mo FE, and Lau LF (2001). The angiogenic factor Cyr61 activates a genetic program for wound healing in human skin fibroblasts. J Biol Chem 276:47329-47337.

Frazier K, Williams S, Kothapalli D, Klapper H, and Grotendorst GR (1996). Stimulation of fibroblast cell growth, matrix production, and granulation tissue formation by connective tissue growth factor. J Invest Dermatol 107:404-411.

Grzeszkiewicz TM, Lindner V, Chen N, Lam SC, and Lau LF (2002). The angiogenic factor cysteine-rich 61 (CYR61, CCN1) supports vascular smooth muscle cell adhesion and stimulates chemotaxis through integrin $\alpha_{6} \beta_{1}$ and cell surface heparan sulfate proteoglycans. Endocrinology 143:14411450 .

Hamet P, Pausova Z, Adarichev V, Adaricheva K, and Tremblay J (1998). Hypertension: Genes and environment. J Hypertens 16:397-418.

Hatakeyama H, Miyamori I, Fujita T, Takeda Y, Takeda R, and Yamamoto H (1994). Vascular aldosterone: Biosynthesis and a link to angiotensin II-induced hypertrophy of vascular smooth muscle cells. J Biol Chem 269:24316-24320.

Hilfiker A, Hilfiker-Kleiner D, Fuchs M, Kaminski K, Lichtenberg A, Rothkotter HJ, Schieffer B, and Drexler H (2002). Expression of CYR61, an angiogenic immediate early gene, in arteriosclerosis and its regulation by angiotensin II. Circulation 106:254-260.

Hishikawa K, Nakaki T, and Fujii T (2000). Connective tissue growth factor induces apoptosis via caspase 3 in cultured human aortic smooth muscle cells. Eur J Pharmacol 392:19 22.

Hishikawa K, Oemar BS, Tanner FC, Nakaki T, Fujii T, and Luscher TF (1999). Overexpression of connective tissue growth factor gene induces apoptosis in human aortic smooth muscle cells. Circulation 100:2108-2112.

Ikeda K, Nara Y, and Yamori Y (1991). Indirect systolic and mean blood pressure determination by a new tail cuff method in spontaneously hypertensive rats. Lab Anim 25:26-29. 
Ito T and Sakaki Y (1999). Fluorescent differential display: A fast and reliable method for message display polymerase chain reaction. Methods Enzymol 303:298-309.

Jay P, Berge-Lefranc JL, Marsollier C, Mejean C, Taviaux S, and Berta $P$ (1997). The human growth factor-inducible immediate early gene, CYR61, maps to chromosome 1p. Oncogene 14:1753-1757.

Kireeva ML, Mo FE, Yang GP, and Lau LF (1996). Cyr61, a product of a growth factor-inducible immediate-early gene, promotes cell proliferation, migration, and adhesion. Mol Cell Biol 16:1326-1334.

Kolesnikova TV and Lau LF (1998). Human CYR61-mediated enhancement of bFGF-induced DNA synthesis in human umbilical vein endothelial cells. Oncogene 16:747-754.

Kunz R, Kreutz R, Beige J, Distler A, and Sharma AM (1997). Association between the angiotensinogen 235Tvariant and essential hypertension in whites: A systematic review and methodological appraisal. Hypertension 30: 1331-1337.

Latinkic BV, O'Brien TP, and Lau LF (1991). Promoter function and structure of the growth factor-inducible immediate early gene cyr61. Nucleic Acids Res 19:3261-3267.

Lau LF and Lam SC (1999). The CCN family of angiogenic regulators: The integrin connection. Exp Cell Res 248:44-57.

Martinerie C, Chevalier G, Rauscher FJ III, and Perbal B. (1996). Regulation of nov by WT1: A potential role for nov in nephrogenesis. Oncogene 12:1479-1492.

Nakagawara K, Mori M, Takasawa S, Nata K, Takamura T, Berlova A, Tohgo A, Karasawa T, Yonekura H, Takeuchi T, and Okamoto $H$ (1995). Assignment of CD38, the gene encoding human leukocyte antigen CD38 (ADP-ribosyl cyclase/cyclic ADP-ribose hydrolase), to chromosome $4 \mathrm{p} 15$. Cytogenet Cell Genet 69:38-39.

O'Brien TP, Yang GP, Sanders L, and Lau LF (1990). Expression of cyr61, a growth factor-inducible immediate-early gene. Mol Cell Biol 10:3569-3577.

Oemar BS, Werner A, Garnier JM, Do DD, Godoy N, Nauck M, Marz W, Rupp J, Pech M, and Luscher TF (1997). Human connective tissue growth factor is expressed in advanced atherosclerotic lesions. Circulation 95:831-839.
Okamoto K and Aoki K (1963). Development of a strain of spontaneously hypertensive rats. Jpn Circ J 27:282-293.

Perbal B, Martinerie C, Sainson R, Werner M, He B, and Roizman B (1999). The C-terminal domain of the regulatory protein NOVH is sufficient to promote interaction with fibulin 1C: A clue for a role of NOVH in cell-adhesion signaling. Proc Natl Acad Sci USA 96:869-874.

Saad Y, Garrett M, and Rapp J (2001). Multiple blood pressure QTL on rat chromosome 1 defined by Dahl rat congenic strains. Physiol Genomics 4:201-214.

Sanger F, Nicklen S, and Coulson AR (1977). DNA sequencing with chain-terminating inhibitors. Proc Natl Acad Sci USA 74:5463-5467.

Schultheis PJ, Clarke LL, Meneton P, Miller ML, Soleimani M, Gawenis LR, Riddle TM, Duffy JJ, Doetschman T, Wang T, Giebisch G, Aronson PS, Lorenz JN, and Shull GE (1998). Renal and intestinal absorptive defects in mice lacking the NHE3 $\mathrm{Na}^{+} / \mathrm{H}^{+}$exchanger. Nat Genet 19:282-285.

Shimo T, Nakanishi T, Kimura Y, Nishida T, Ishizeki K, Matsumura T, and Takigawa M (1998). Inhibition of endogenous expression of connective tissue growth factor by its antisense oligonucleotide and antisense RNA suppresses proliferation and migration of vascular endothelial cells. J Biochem (Tokyo) 124:130-140.

Tamura I, Rosenbloom J, Macarak E, and Chaqour B (2001). Regulation of Cyr61 gene expression by mechanical stretch through multiple signaling pathways. Am J Physiol Cell Physiol 281:C1524-1532.

Tse CM, Brant SR, Walker MS, Pouyssegur J, and Donowitz $M$ (1992). Cloning and sequencing of a rabbit CDNA encoding an intestinal and kidney-specific $\mathrm{Na}^{+} / \mathrm{H}^{+}$exchanger isoform (NHE-3). J Biol Chem 267:9340-9346.

Wakeland E, Morel L, Achey K, Yui M, and Longmate J (1997). Speed congenics: A classic technique in the fast lane (relatively speaking). Immunol Today 18:472-477.

Yonekura H, Migita H, Sakurai S, Wang H, Harada S, Abedin MJ, Yamagishi S, and Yamamoto H (1999). Antisense display: A method for functional gene screening: Evaluation in a cell-free system and isolation of angiogenesis-related genes. Nucleic Acids Res 27:2591-2600. 